\title{
The Effect of Blade Number on Small Horizontal Axis Wind Turbine (HAWT) Performance: An Experimental and Numerical Study
}

\author{
Andi F. Sudarma, Muhammad Kholil, Subekti Subekti, and Indra Almahdy
}

\begin{abstract}
The effect of blade number on small Horizontal Axis Wind Turbine (HAWT) has been studied experimentally and numerically in this research. The turbine blade is made of a flat metal sheet and the tip was formed to shape a winglet. The 5-blades turbine was tested inside a wind tunnel for performance investigation at different wind speeds. The experiment was conducted under various wind speed, i.e. 3.5 $\mathrm{m} / \mathrm{s}, 3.9 \mathrm{~m} / \mathrm{s}, 4.3 \mathrm{~m} / \mathrm{s}, 4.6 \mathrm{~m} / \mathrm{s}$ dan $5 \mathrm{~m} / \mathrm{s}$. Furthermore, three wind turbines geometry with different blade number $(3,4$, and 5 blades) were built for numerical study purpose by using Ansys Fluent and the results were compared to the experimental one. The results show that the blade number does increase the wind turbine torque and there is also more power generated from the turbine with more blade numbers since torque is related to pressure. Moreover, the winglet helps the blade to retain the flow and increases the pressure on the blade surface. However, the experimental measurements obtained were smaller than the numerical predictions about $50 \%$ on the average since more unidentified losses existed and not accounted for the calculation.
\end{abstract}

Index Terms - Computational fluid dynamics, blades number, horizontal axis wind turbine, wind energy, performance.

\section{INTRODUCTION}

The demand for electrical energy continuously grows every year [1], it was projected that world energy demand would increase by approximately 50\% between 2018 and 2050 [2]. Currently, $85 \%$ of the world's energy consumption depends on fossil fuels, the principal $\mathrm{CO}_{2}$ emission source [3], [4]. Moreover, the fossil fuel industry, as the primary producer and consumer of energy, is the leading contributor to climate change. On the other hand, petroleum-based fuels are nonrenewable, and the reserves continuously depleted. In order to fulfill the demand, humans must find other sources of energy that more eco-friendly to depend on. Electrical generation from renewable energy will be a prospective solution to fulfill the demand since the sources were abundant [5].

Wind energy is one of the fastest-growing energy sources in the world with zero-emission and pollution. The wind turbine produces electricity by converting the wind's kinetic energy into mechanical energy. Wind energy is more reliable

Manuscript received February 25, 2020; revised October 13, 2020.

Andi F. Sudarma and Subekti Subekti are with the Department of Mechanical Engineering, Universitas Mercu Buana, Jakarta, 11650, Indonesia (e-mail: andi.firdaus@mercubuana.ac.id, subekti@mercubuana.ac.id).

Muhammad Kholil and Indra Almahdy are with the Department of Industrial Engineering, Universitas Mercu Buana, Jakarta, 11650, Indonesia (e-mail: m.kholil@mercubuana.ac.id,indraal@mercubuana.ac.id). than other renewable energy sources since it can generate power 24 hours a day and not depend on sunlight. Compared to solar energy, as an example, which is dependent on sunlight and weather conditions.

The wind power manufacturer generally uses a horizontal or vertical wind turbine to generate power from wind flow. Commonly, it consists of blades pointed into the wind and connected to the rotor and then to a generator. This system requires larger blades, taller towers, and more areas of land to gain higher energy output. To capture more wind energy, manufacturers mounted the rotor at the top of the tall tower since wind speed near the ground surface was very low. However, complaints of a threat to wildlife, noise and visual pollution, and high production and maintenance cost continues to obstruct the development [6]. As the solution, SheerWind developed Invelox that offers a novel concept of wind power generation, especially for low wind speed applications [7]. The design, as shown in Fig. 1, captures wind with a funnel and directs it through a shrouded venturi to increase the speed. The turbine generator is placed safely at ground level to convert the energy into electrical energy (reduced installation and maintenance cost). The invention of Invelox influenced other researchers to study the system that can enhance the wind power from the flow at the atmospheric boundary layer.

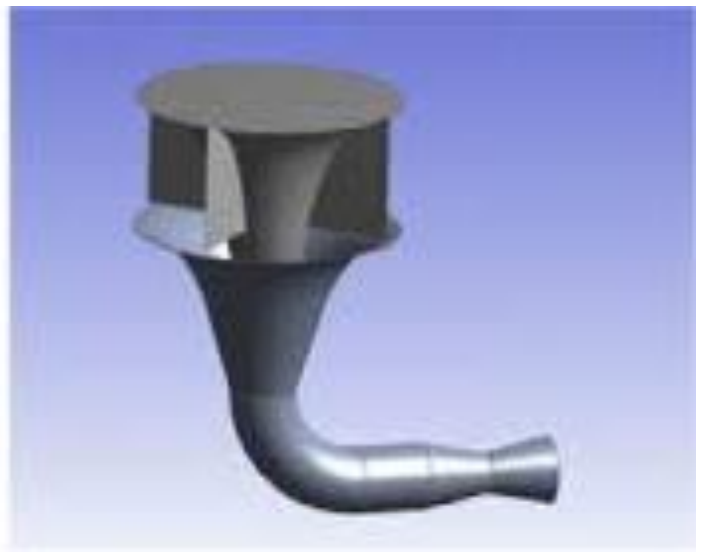

Fig. 1. SheerWind Invelox wind power system. (Source: SheerWind, 2012).

The information gathered from the experimental test tend to be limited since many parameters are not accessible because of the limitation of equipment capabilities or adequate tools. The use of CFD can help to provide detailed data on flow characteristics that very useful for understanding the flow behavior [8]. The investigation of Invelox numerically has been conducted to study the advantages in terms of power generation compared to the 
conventional wind generation system. The simulation shows that the wind speed at the venturi section gives 6-8 times more power [9]. Furthermore, the application of wind turbines for a small scale has been investigated to know the effect of the blade number on the performance [10]. The study shows that the number of blades affects the performance, with a more significant number of blades, give better results [11]. However, the number of blades should be determined carefully to obtain the cost-benefit and weight reduction [12].

Small scale wind turbine experimental and numerical investigation has been reported in this article. This work aims to investigate the influence of the blade number on the wind turbine performance for the future application inside an Invelox venturi section and determine the most effective blade number for the design. Three turbine models with a different number of winglet blades were compared in various wind speeds. A mathematical model introduced for predicting the pressure distribution on the surface of the blade to obtain the power coefficient.

\section{Wind TURBINE POWER CALCULATION}

The power generated by the wind turbine is a very important parameter that has to be predicted before it is actually produced. The turbine behavior under different wind speed is another point that has to be studied in order to understand the estimated energy values. Reference [13] describes the mathematical model of wind turbine power and energy output. It begins with the equation of work $(W)$ that is equal to the amount of energy transferred or converted by force, i.e.:

$$
W=E=F s
$$

where $F$ is the applied force and $s$ is objects' displacement. Newtons' second law of motion describes that force is equal to mass $(m)$ times acceleration $(a)$. Hence, work can be rewritten as;

$$
E=m a s
$$

From the equation of motion, the acceleration $(a)$ can be written as;

$$
a=\frac{\left(v^{2}-u^{2}\right)}{2 s}
$$

where $v$ is the wind speed, and $u$ is the object velocity. Since the object was initially at stationary condition, i.e., $u=0$, the motion equation can be simplified as;

$$
a=\frac{v^{2}}{2 s}
$$

Hence, the kinetic energy of an object in motions can be described by substituting (2) in to (1).

$$
E=\frac{1}{2} m v^{2}
$$

Thus, the energy flow rate or the power generated by wind is defined as;

$$
P=\frac{d E}{d t}=\frac{1}{2} v^{2} \frac{d m}{d t}
$$

As mass flow rate can be written as;

$$
\frac{d m}{d t}=\rho A v
$$

Furthermore, by substituting the mass flow rate equation in to (3), the power equation can be written as;

$$
P=\frac{1}{2} \rho A v^{3}
$$

And by applying Betz law [14] into the power equation, the extractable power by the wind turbine can be estimated as follows;

$$
P_{W T}=0.59 \frac{1}{2} \rho A v^{3}
$$

where $A$ is the turbine swept area, as shown in Fig. 2.

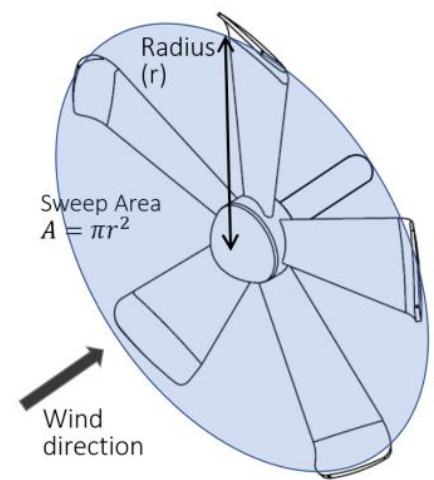

Fig. 2. The swept area of the turbine.

\section{METHODOLOGY}

\section{A. Experimental Setup}

The wind turbine tests, as shown in Fig. 3, were conducted at the Mechanical Engineering Laboratory, Universitas Mercu Buana. The low-speed wind tunnel consists of a square test section with 0.8 meter width and 3 meter length. A large bell mouth screen and a honeycomb flow straightener were mounted at the wind tunnel inlet.

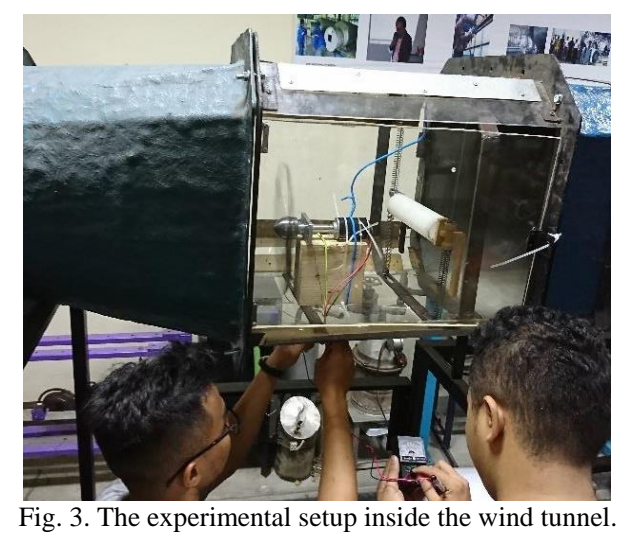




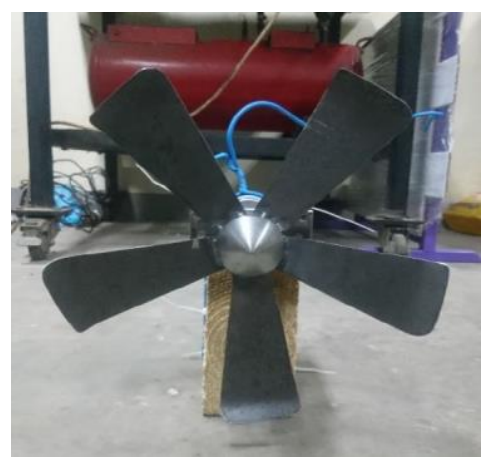

Fig. 4. The wind turbine with 5 blades for wind tunnel test.

A wind turbine model, shown in Fig. 4, was fabricated for the current investigation consisting of 5 blades made of a flat metal sheet. The turbine blade has an overall $300 \mathrm{~mm}$ diameter. The blade tip was formed to shape a winglet with the angle of pitch 10 degrees. The turbine then tested inside the wind tunnel for performance investigation at different wind speeds, i.e., $3.5 \mathrm{~m} / \mathrm{s}, 3.9 \mathrm{~m} / \mathrm{s}, 4.3 \mathrm{~m} / \mathrm{s}, 4.6 \mathrm{~m} / \mathrm{s}$ dan $5 \mathrm{~m} / \mathrm{s}$. The digital anemometer was used to measure the wind speed inside the tunnel. The turbine shaft was connected to a 12VDC small brushed permanent magnet (PMDC) generator with armature resistant $\left(I_{a}\right) \quad 0.43 \Omega$. The generated output power was measured by using a digital power meter, and the shaft speed was monitored by using a non-contact tachometer.

\section{B. Numerical Model Application}

Furthermore, a CAD geometry was constructed to model the 5-blades turbine based on the actual wind turbine dimension. An unstructured mesh was built to model the wind tunnel domain and then subtracted by the 3D wind turbine geometry using Boolean operation [15]. The turbines were simulated in various wind velocity using ANSYS Fluent, and the results were compared to the experimental one. The boundary conditions of the domain were set to match the experimental conditions. Shear Stress Transport (SST) turbulence model was used to model the transient viscous flow [16], [17]. The second and the third model, as shown in Fig. 5, was constructed with different blade numbers ( 3 and 4 blades) and simulated numerically under the identical boundary condition and numerical setup.

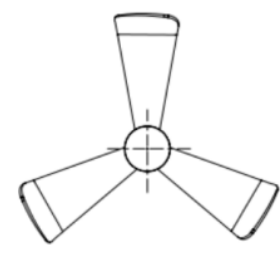

(a)

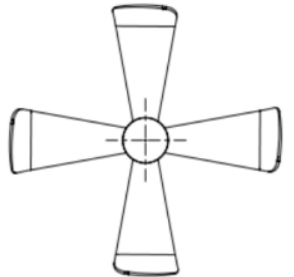

(b)
Fig. 5. The wind turbine with different blade number for numerical simulation; (a) 3 blades, (b) 4 blades.

\section{RESUlTS AND DISCUSSION}

The wind turbine performance and effect of various blade numbers are discussed here. The turbine was investigated experimentally inside a wind turbine at various wind velocity of $3.5 \mathrm{~m} / \mathrm{s}, 3.9 \mathrm{~m} / \mathrm{s}, 4.3 \mathrm{~m} / \mathrm{s}, 4.6 \mathrm{~m} / \mathrm{s}$ dan $5 \mathrm{~m} / \mathrm{s}$. Furthermore, the numerical simulation has been performed with blade number variation of 3, 4, and 5 blades. Both results compared and discussed below.

\section{A. Effect of Blade Number}

Fig. 6 shows the comparison of pressure contour for different turbine designs. The results were obtained from the numerical simulation at a wind velocity of $5 \mathrm{~m} / \mathrm{s}$. The results show that the pressure concentration does exist at the blade tip. The figures demonstrate that the winglet helps the blade to retain the flow and increases the pressure on the blade surface. More blades number shows more pressure that occurred on the turbine surface. As a result, more power generated from the turbine with more blade numbers since torque is related to pressure.

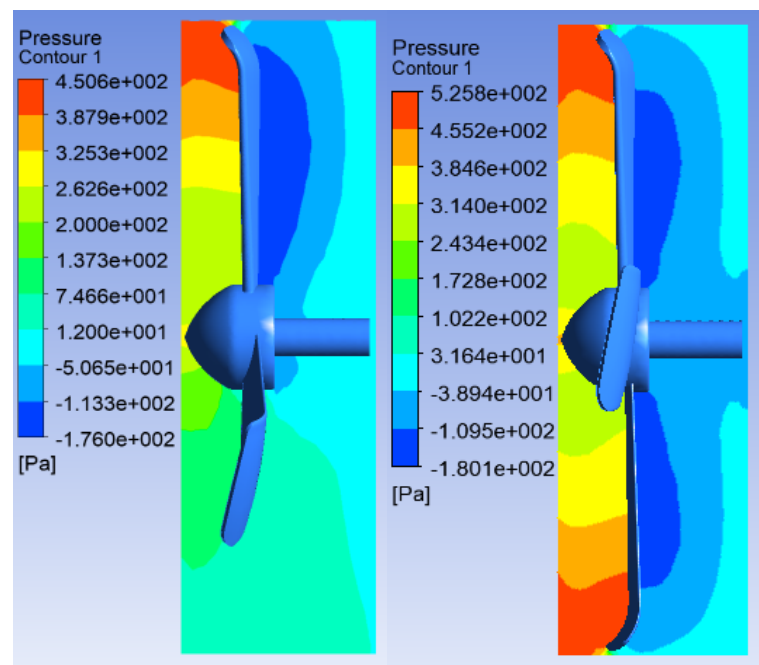

(a)

(b)

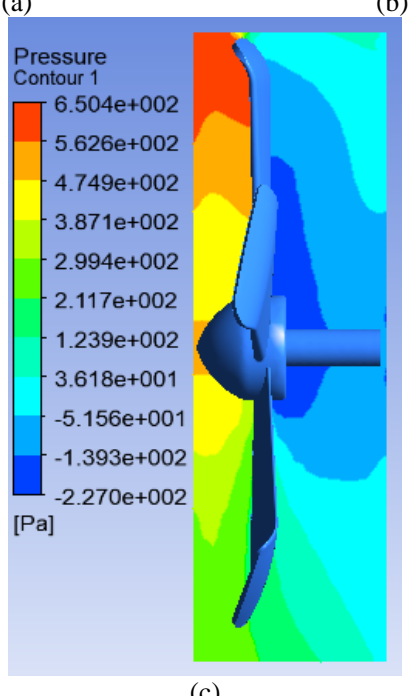

(c)

Fig. 6. Pressure contour at turbine with different blade number; (a) 3 blades, (b) 4 blades, and (c) 5 blades

For the investigation of blade number effect on torque and power output, the numerical results were presented in Fig. 7. The power extracted from the wind turbine was transmitted to the generator by the rotating shaft in the form of torque. The estimated power was calculated by multiplying the torque, angular velocity, and power coefficient (Betz's number). The results show that the pressure, power, and torque increased as the higher blade number since torque is the summation of pressure and viscous stress integration [18]. It is shown that the power was increased by $32 \%$ as the 
number of blades increased from 3 to 4 and 4 to 5 . Similar results have been reported to show that the higher number of blade turbine has a better performance [10], [12], [19]. However, the maximum blade number is limited to specific value, since increasing the blade number will give additional weight [12].

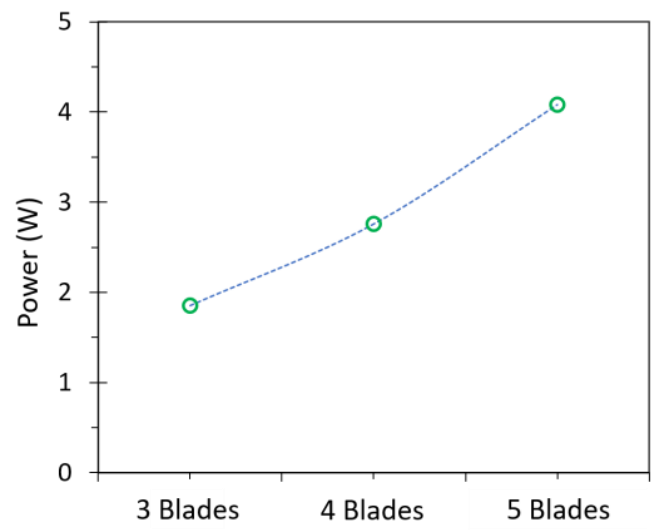

Fig. 7. Comparison of mechanical power results from numerical simulation with different blades design.

\section{B. Effect of Wind Speed}

Fig. 8 shows the comparison of power output from the numerical, experimental, and theoretical results of the various turbine design. The experimental results obtained by reading the power output from the generator connected to the rotor and the theoretical results acquired from the multiplication of air density, rotor swept area, power by three of wind velocity, and Betz number [14] as defined in (6). Betz law states that the theoretical power output is the maximum power that can be produced by a wind turbine system. The result shows that increasing the wind speed by 1 $\mathrm{m} / \mathrm{s}$ would double the power generated by the turbine. It would be interesting to expand the study for a wind turbine with more blade number to know the critical point that effect on the performance changes for future work.

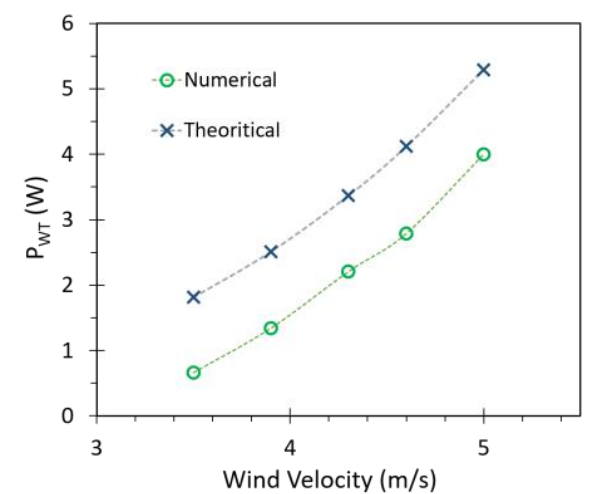

Fig. 8. Mechanical power generated from different wind velocity.

\section{Effect of Generator Losses}

Many factors contributed to energy losses, such as aerodynamic and generator resistances, was occurred during the wind energy conversion [20]. In this calculation, the losses attributed by the generator were considered since turbine losses were already included in Betz limit.

Fig. 9 demonstrates the mechanical power conversion in to electrical in the generator. The figure shows that not all mechanical power converted to electrical power, and the output reduced by the energy losses. The major losses that occurred on the generator can be categorized into the following groups; shunt filed excitation, brush drop and stray load, armature winding, brush friction and part of the armature iron, mechanical windage, and part of the electromagnetic. As a result, the generator output power measurements are likely to be lower than the mechanical power transferred by the wind turbine rotor. The following major losses were described and accounted for the output energy reduction. These losses are; 1) copper losses that caused by the electric current flows in a conductor with limited resistance; 2) iron/core losses, including the hysteresis and eddy current losses from the magnetic field; 3) mechanical losses which caused mostly by friction in bearings and brushes and rotational air-friction. Some previous studies [21]-[23] were benefited by estimating the power losses from the known equations as follow;

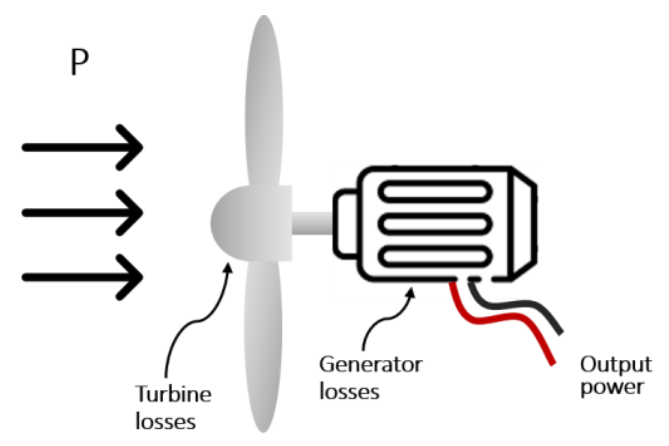

Fig. 9. Energy losses in the wind turbine.

Copper losses:

Core losses:

Mechanical losses:

$$
\begin{aligned}
& P_{\text {armature }}=I_{a}^{2} R_{a} \\
& P_{f m}=V I_{f m}
\end{aligned}
$$

where

$I_{a}=$ armature current $(\mathrm{A})$

$R_{a}=$ armature resistant $(\Omega)$

$V=$ Voltage $(\mathrm{V})$

$I_{f m}=$ magnetic field current $(\mathrm{A})$

$F=$ radial force in the bearing $(\mathrm{N})$

$v=$ perimeter speed of bearing $(\mathrm{m} / \mathrm{s})$

$d=$ roller diameter $(\mathrm{m})$

However, the losses computation, as described in the above formula, requires complete design information. For more computational simplification, Safiuddin [24] proposes a model of expression for determining the rated losses from DC machine based on statistical multiple regression techniques as shown in (7). The expression was a function of rotational speed $(\omega)$ in RPM, armature volume $d^{2} l$ (DSQL) in cubic, and the percentage of armature droop (delta).

$$
\begin{gathered}
\% \text { losses }=3.832+\frac{2545.22}{R P M}+\frac{5751.54}{D S Q L} \\
+0.389 \text { delta }-1.424 \frac{R P M}{D S Q L}-0.2795 \frac{D S Q L}{R P M}
\end{gathered}
$$


where delta $=100 I_{r} R_{a} / V_{r}$

The mechanical power predictions obtained from numerical simulation were subtracted by the losses calculated from the above equation, and results were compared to the experimental measurements and presented in Fig. 10. The figure shows that the experimental results were lower than numerical prediction results about $50 \%$ on the average. As an accumulative result, the actual generator efficiency was lower than the prediction since there were more unidentified losses that occurred and not accounted for the calculation. From the studies previously conducted, Kang and Meneveau [25] suggest that measuring the output power from the generator can lead to misleading information about the performance of the wind turbine and questioned the validity of the result. For future works, it was essential to measure the rated power losses of the generator for a better understanding of the wind turbine performance. The better solution to solve the problem was by measure the shaft torque directly using a high-precision rotary torque sensor as performed by Bastankhah and Porté-Agel [26].

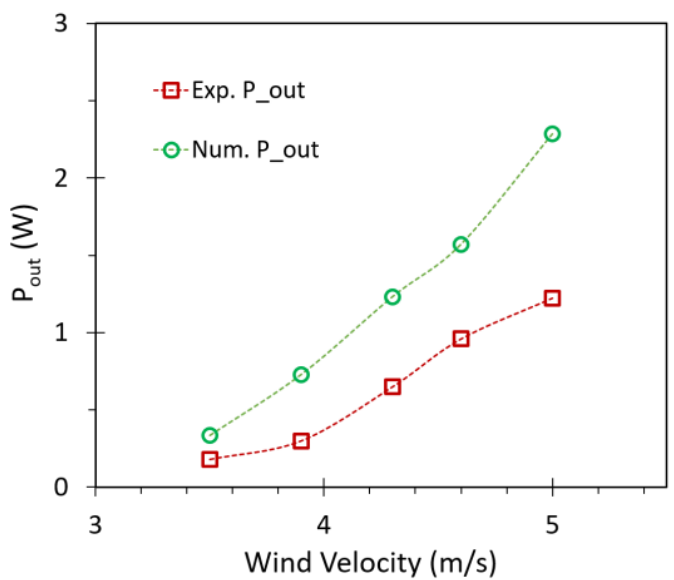

Fig. 10. Comparison of numerical and experimental power output at different wind velocity.

\section{CONCLUSION}

The effect of blade number on small Horizontal Axis Wind Turbine (HAWT) performance has been studied experimentally inside a wind tunnel and numerically using a commercial software. The results show that the blade number does increase the wind turbine torque and output power. The winglet affects the performance by increasing the pressure on the blade surface and concentrating the wind flow at the blade tip. The power generated from experimental measurements was lower than the numerical prediction. The energy losses from the wind turbine and generator contributed to performance reduction.

\section{CONFLICT OF INTEREST}

The authors declare that there is no conflict of interest regarding the publication of this article.

\section{AUTHOR CONTRIBUTIONS}

AFS wrote the manuscript and conducted the CFD analysis; MK fabricated and assembled the turbine; SS and his team performed the experiment using a wind tunnel and analyzed the experimental data; and IA provided the measurement tools and other experimental equipment. All authors had approved the final version.

\section{ACKNOWLEDGMENT}

The authors gratefully acknowledge financial support from Research Center of Universitas Mercu Buana. The experiment was conducted at Department of Mechanical Engineering Laboratory, Universitas Mercu Buana, and the support was gratefully appreciated.

\section{REFERENCES}

[1] Subekti, A. Hammid, and A. Surjosatyoe, "The use of flow-induced vibration as an alternative resource of new power plant in Indonesia," E3S Web of Conferences, vol. 67, p. 1017, 2018.

[2] A. Kahan, "EIA projects nearly $50 \%$ increase in world energy usage by 2050, led by growth in Asia," Today in Energy, U.S. Energy Information Administration, 2019.

[3] C. Okkerse and H. V. Bekkum, "From fossil to green," Green Chem., vol. 1, no. 2, pp. 107-114, 1999.

[4] H. Li, H. C. Jenkins-Smith, C. L. Silva, R. P. Berrens, and K. G. Herron, "Public support for reducing US reliance on fossil fuels: Investigating household willingness-to-pay for energy research and development," Ecol. Econ., vol. 68, no. 3, pp. 731-742, 2009.

[5] A. A. Luthfie, S. E. Pratiwi, and P. Hidayatulloh, "Hydrocoil turbine performance at $3 \mathrm{~m}, 4 \mathrm{~m}$, and $5 \mathrm{~m}$ head analysis using computational fluid dynamics method," in IOP Conference Series: Materials Science and Engineering, vol. 343, no. 012024, 2018.

[6] R. Saidur, N. A. Rahim, M. R. Islam, and K. H. Solangi, "Environmental impact of wind energy," Renew. Sustain. energy Rev. vol. 15, no. 5, pp. 2423-2430, 2011.

[7] D. Allaei and Y. Andreopoulos, "Invelox: Description of a new concept in wind power and its performance evaluation," Energy, vol. 69, pp. 336-344, May 2014.

[8] A. F. Sudarma and M. H. Morsy, "RANS numerical simulation of lean premixed bluff body stabilized combustor: Comparison of turbulence models," J. Therm. Eng., vol. 3, no. 6, pp. 1561-1573, Nov. 2017.

[9] D. Allaei, "Using CFD to predict the performance of innovative wind power generators," in Proc. 2012 Comcol Conf., 2012.

[10] S. H. Wang and S. H. Chen, "Blade number effect for a ducted wind turbine," J. Mech. Sci. Technol., vol. 22, no. 10, p. 1598, Oct. 2008.

[11] A. Rachman, R. Balaka, J. Delly, and Y. Gunawan, "Simulation on the effect of the blade number on the rotational characteristic on a horizontal axis river current turbine," Int. J. Energy Environ. Eng., vol. 4, no. 32, Aug. 2013.

[12] F. Mühle, M. S. Adaramola, and L. Sretran, "The effect of the number of blades on wind turbine wake - A comparison between 2-and 3-bladed rotors," Journal of Physics: Conference Series, vol. 753, 2016.

[13] RWE npower renewables, "Wind turbine power calculations," Mech. Electr. Eng. Power Ind. R. Acad. Eng., 2012.

[14] A. Betz, Introduction to the Theory of Flow Machines, Oxford, UK, Pergamon Press, 1966, ch. 66.

[15] G. Mei and J. C. Tipper, "Simple and robust boolean operations for triangulated surfaces," arXiv Prepr. arXiv1308.4434, 2013.

[16] F. R. Menter, "Two-equation eddy-viscosity turbulence models for engineering applications," AIAA J., vol. 32, no. 8, p. 1598, Aug. 1994.

[17] F. R. Menter and Y. Egorov, "A scale-adaptive simulation model using two-equation models," AIAA Pap., vol. 1095, p. 2005, 2005.

[18] K. N. Lucas, J. O. Dabiri, and G. V. Lauder, "A pressure-based force and torque prediction technique for the study of fish-like swimming," PLoS One, vol. 12, no. 12, Dec. 2017.

[19] M. M. Duquette and K. D. Visser, "Numerical implications of solidity and blade number on rotor performance of horizontal-axis wind turbines," J. Sol. Energy Eng. Trans. ASME, vol. 125, no. 4, pp. 425-432, Nov. 2003.

[20] O. P. Mahela and A. G. Shaik, "Comprehensive overview of grid interfaced wind energy generation systems," Renew. Sustain. Energy Rev., vol. 57, pp. 260-281, 2016.

[21] M. Bastankhah and F. Porté-Agel, "A wind-tunnel investigation of wind-turbine wakes in yawed conditions," Journal of Physics: Conference Series, vol. 625, no. 1, p. 12014, 2015. 
[22] V. P. Stein and H.-J. Kaltenbach, "Wind-tunnel modelling of the tip-speed ratio influence on the wake evolution," Journal of Physics: Conference Series, vol. 753, no. 3, p. 32061, 2016.

[23] J. Murata et al., "Experimental and numerical investigation of the effect of turbulent inflow on a horizontal axis wind turbine (Part II: Wake characteristics)," Energy, vol. 113, pp. 1304-1315, 2016.

[24] M. Safiuddin, "Evaluation of losses in DC machines - A statistical approach," IEEE Trans. Ind. Appl., vol. 26, no. 2, pp. 252-258, 1990.

[25] H. S. Kang and C. Meneveau, "Direct mechanical torque sensor for model wind turbines," Meas. Sci. Technol., vol. 21, no. 10, p. 105206 , 2010.

[26] M. Bastankhah and F. Porté-Agel, "A new miniature wind turbine for wind tunnel experiments. Part I: Design and performance," Energies, vol. 10, no. 7, p. $908,2017$.

Copyright $\odot 2020$ by the authors. This is an open access article distributed under the Creative Commons Attribution License which permits unrestricted use, distribution, and reproduction in any medium, provided the original work is properly cited (CC BY 4.0).

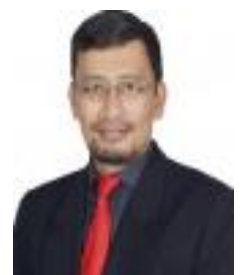

Andi F. Sudarma is a senior lecturer at the Department of Mechanical Engineering, Universitas Mercu Buana, Indonesia. Previously he was enrolled as a design engineer at steel construction company for years before pursuing his degree. He completed his graduate studies at King Saud University, focused on thermal and fluids. His researches interests, including computational fluid dynamics, combustion process, fluid mechanics and boundary layer, etc. His published research articles mostly related to CFD and combustion. He teaches courses for the undergraduate program, including renewable energy, computational fluid dynamics, combustion engine, applied thermodynamics, etc.

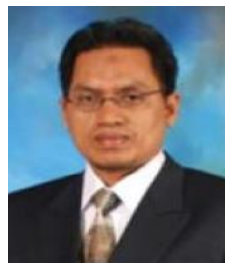

Muhammad Kholil is a senior lecturer at the Department of Industrial Engineering. Currently, he is a vice dean of Engineering Faculty, Universitas Mercu Buana, Indonesia. He graduated from Institute Teknologi Sepuluh November and pursuing his Ph.D. at Universiti Tun Hussein Onn Malaysia (UTHM). His researches interest, including quality management and lean manufacturing and has published many research articles related to these topics. He involved in publishing a book entitled Introduction in Industrial Engineering, published in Bahasa Indonesia by Graha Ilmu Press, and another book entitled Six Sigma: Quality for Business Improvement.

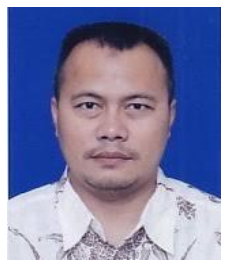

Subekti Subekti is a senior lecturer at the Department of Mechanical Engineering, Universitas Mercu Buana, Indonesia. He has a professional background for years and involved in many researcher projects for industrial purposes. He attended a graduate program at Institut Teknologi Bandung in 2003, specialized in mechanical engineering. After obtained the degree, he was enrolled as a research assistant at Robotic Dynamic Laboratory, Hokkaido University, Japan, and involved in joint-research focused on high-temperature sensors. In 2019, he was awarded as the best lecturer from the Faculty of Engineering, Universitas Mercu Buana. His researches were published in a local and international journal in a specific area, including $\mathrm{CNC}$ machine, control system, renewable energy, vibration analysis, etc.

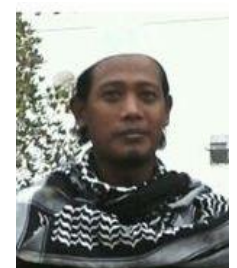

Indra Almahdy is a senior lecturer at the Department of Industrial Engineering, Universitas Mercu Buana Indonesia. $\mathrm{He}$ has a professional background and involved in many researcher projects for industrial applications. He attended a graduate program specialized in industrial engineering. His researches interest, including strategic industrial information, quality control, production planning and control, production performance, industrial management, and has published many research articles related to these topics. He involved in translating a book entitled Operations Management by Jay Heizer and Barry Render into Bahasa Indonesia and published by Salemba Empat Press in 2006. He teaches courses for the undergraduate program, including information system management, strategic management, effective production system, etc. 